\title{
Transparency in the structure of the Catalan communication system: The Communication and Culture Barometer
}

\author{
Andreu Casero Universitat Jaume I de Castelló
}

\begin{abstract}
What and what for: the need for a barometer
At the beginning of 2003, the Catalan Space for Communication and Culture (ESCACC) Foundation initiated a long-awaited project: an audience measurement study specifically addressed to Catalan-speaking areas (Catalonia, the Valencian Country and the Balearic Islands). Following a series of initial reports, the Communication and Culture Audiences Foundation (FUNDACC) was created, with the aim of promoting a new instrument known as the Communication and Culture Barometer. Fieldwork began in 2007 to gather the first data, which was published on 28 February 2008. This date represents a remarkable watershed: the end of opacity in the Catalan communication system, which finally gained access to rigorous information on the consumer habits and media and cultural practices occurring within its boundaries.
\end{abstract}

The reasons behind the creation of the barometer are diverse and complex, and therefore must be sought at various levels. The first of these is the conviction that the Catalan geographical area, understood in its widest sense, enjoys a set of specific cultural features that make it unique and set it apart from other cultural contexts (Gifreu 2006). This fact affirms the existence of a singular communication and cultural reality, marked amongst other aspects by the presence of its own language (Catalan) and a defined cultural identity. These aspects generate the appearance of a cultural dynamic with a certain autonomy vis-à-vis the Spanish culture: a circumstance that has led various authors to define this situation in terms of 'a Catalan communication space' (Gifreu 1983; Gifreu and Corominas 1991; Gifreu 2007).

Despite this specific differentiated configuration, Catalan culture and its dynamics have remained hidden (Cardús 2008: 226) and any detailed knowledge of its own consumer practices and habits have been foggy at best, which has considerably hindered the consolidation of local cultural industries. Without specific data on these issues, the economic exploitation and optimisation of local media business is a complex process. The invisibility of the Catalan communication system, understood as a market, must be sought in the influence that the political sphere has over communication structures, amongst other factors. In recent decades, the European Union has abandoned the development of communication policies that address the communication, cultural and linguistic realities of stateless nations, leaving the management and administration of cultural diversity in the hands of central states (Moragas 2008: 280). This situation has had a particular impact on the specific communication systems found within the Spanish context, such as the Catalan, Basque and Galician systems. As a direct consequence, these spheres have been defined 
as 'peripheral cultures' (Cardús 2008: 225), with all the marginalisation and isolation that the centrally defined dynamics of cultural industries imply.

Nonetheless, it is clearly evident that the Catalan communication system, in its broadest sense, constitutes a cultural reality of 13 million people. A priori, the existence of this potential audience would suggest that a market provided with sufficient economic weight should feasibly be able to support a series of local cultural industries. However, in order to lay the foundations for this market, specific data on Catalan media consumption and audiences are, once again, vital. Without these data, advertising revenue, the mainstay of most media financing, lacks a suitable framework within which to operate and grow. Hence, the second crucial reason behind the creation of the barometer was the need to obtain audience data on the Catalan communication system using technically rigorous methodology designed to provide information at a micro level in the local and regional field.

The main questionnaire-based audience measurement system used in Spain is the Estudio General de Medios (General Media Study, EGM), which operates at a state level. It is therefore more concerned with the Spanish communication system as a whole than with the various local or regional systems, such as the Catalan system. This approach is reflected in both the design of the interviewee sample - only 11,000 people in Catalonia as compared to the 29,828 covered by the barometer in the same area - and in the results it produces. These results systematically ignore the reality of Catalan communication, and thus result in significant omissions: the EGM does not include the audiences of Catalan public radio and television (TV3 and Catalunya Ràdio) in the Balearic Islands and the Valencian Country (Busquet 2008: 188), where, despite reaching beyond existing legal boundaries, their broadcasts are received. Consequently, this type of statebased system, while useful in determining general patterns for the Spanish system, is inefficient to accurately determine media and cultural consumer habits for local and regional systems such as the Catalan system.

Undertaking to create a system that measures its own audiences is not without risks. So long as the situation remains foggy, certain self-interested assumptions about audience behaviour can still be upheld, but once the fog is dispelled by applying tools that shed light on the matter, for better or worse, the full picture becomes clear. In other words, the existence of specific data allows transparency to penetrate a hitherto opaque communication system. As a result, new growth opportunities open up; as rigorous audience information becomes available, the basis on which advertising revenue is calculated, and weaknesses, previously hidden in the fog, are also uncovered. Nonetheless, the availability of specific in-depth data does make Catalan communication entities and cultural industries competitive (Cardús et al. 2007: 24) in market terms. Those are essential factors for the construction of solid structures able to support a local media and communication system.

\section{How: the barometer methodology}

As mentioned above, the barometer uses a questionnaire-based methodology to obtain data on cultural and communication consumption and the social 
penetration of the Catalan cultural industries. To this end, the main questionnaire is constructed around three large variable study groups. First, the traditional communication media: newspapers, magazines, radio, television and outside advertising. Second, a whole series of relevant cultural industries, from a wide conceptual base, are considered: Internet, music, cinema, video games and mobile telephony. Types of cultural consumption that fall outside the media system are also included in this block, such as live performance and exhibition attendance. Finally, the third block consists of qualitative variables to gather audience information: socio-demographic profile (sex, age, marital status, education, employment situation, income, social class, place of birth, etc.), linguistic profile (skills, usual language, maternal language, etc.), ideological profile (political and national position), lifestyle (cultural and leisure activities, hours of activity and schedule structure) and finally, geographical area of residence.

The barometer's sample universe covers the population over the age of fourteen in all the Catalan-speaking areas. The sample, taken randomly, has a confidence level of 95.5 per cent and an overall margin of error of 0.5 per cent, and consists of 39,159 personal interviews carried out in the individual's home. The size of the sample illustrates the ambition of the audience measurement instrument: by comparison, the EGM - a study with similar methodology although at a state level - carries out 43,741 interviews across the whole of Spain. In addition, the barometer performs continuous fieldwork and publishes its results in three four-monthly stages.

The sample design for the barometer's main questionnaire clearly differentiates between geographical areas. Firstly, it distinguishes a series of areas that comprise the central sphere of its activity from others that come within a secondary sphere. The first group, in which continuous audience interviews are carried out, includes Catalonia, the Valencian Country and the Balearic Islands. In contrast, the second group comprises bordering territories where the language is used, but which fall outside the boundaries of the Catalan communication system. These include the Principality of Andorra, North Catalonia, located inside the French state, and the Western Strip, which forms part of another Spanish region, Aragon. In these three cases, information is gathered twice a year from a sample of 2,533 people (Cardús et al. 2007: 52) as compared to the 39,159 in the central region.

An examination of how the sample is distributed within the areas included in the barometer's central sphere of study is also pertinent. From the technical data (Cardús et al. 2007: 54-55), we can see that there is no direct correlation between the population and the sample in the design of the barometer's main questionnaire. Table 1 shows that while 52 per cent of the inhabitants of the Catalan-speaking areas analysed are found in Catalonia, they account for 76 per cent of the total sample. In contrast, the Valencian Country, despite accounting for 41 per cent of the population, only represents 18 per cent of the sample. Consequently, although Valencian Country data are corrected with an upward weighted index, the methodological design of this instrument can be said to have significant internal imbalances and reveals a predominance of the Catalan-centric 
vision in the conception of the Catalan communication and cultural system. This vision will become further pronounced if claims are confirmed that surveys in the Valencian Country are to be temporarily suspended in 2009 , as stated by the managing director of FUNDACC, Joan Sabaté

\begin{tabular}{|l|l|l|}
\hline & $\begin{array}{c}\text { Population } \\
\text { (total) }\end{array}$ & $\%$ \\
\hline Catalonia & $5,273,904$ & 52 \\
\hline $\begin{array}{l}\text { Valencian } \\
\text { Country }\end{array}$ & $4,202,608$ & 41 \\
\hline $\begin{array}{l}\text { Balearic } \\
\text { Islands }\end{array}$ & 760,379 & 7 \\
\hline
\end{tabular}

\begin{tabular}{|l|l|l|}
\hline & \multicolumn{1}{|c|}{ Sample } & \multicolumn{1}{|c|}{$\%$} \\
\hline Catalonia & 29,828 & 76 \\
\hline $\begin{array}{l}\text { Valencian } \\
\text { Country }\end{array}$ & 6,975 & 18 \\
\hline $\begin{array}{l}\text { Balearic } \\
\text { Islands }\end{array}$ & 2,351 & 6 \\
\hline
\end{tabular}

Source: Author's own, based on data taken from Cardús et al. 2007.

Table 1: Comparison between population and sample in the barometer's central

This sample design bias reappears when a geographical analysis is performed on the divisions of the three large areas in the barometer's main questionnaire. While Catalonia is divided into 41 sections, each corresponding to a comarca or administrative district, the Valencian Country are broken down into just seven large sections despite having a total of 33 comarcas, and the Balearic Islands are divided into three zones. Thus, while this territorial breakdown enables a very detailed data to be gathered on the communication and cultural behaviour of audiences in Catalonia, data quality deteriorates in the other two regions. In this way, a wealth of information is lost on local consumption and media in the Valencian Country and the Balearic Islands, which constitute one of the cornerstones of the Catalan communication system (Moragas 2008: 281).

The barometer's initial results: old certainties, new realities

Although still in its infancy - the first data refer to 2007 - the barometer has already provided some interesting information on cultural consumption and the media diet of audiences in Catalan-speaking areas. These initial results empirically confirm some of the presumptions and peculiarities traditionally attributed to the Catalan communication system, but at the same time, they uncover notable new aspects - all of which provide us with a fresh, detailed picture of the system's structure and operating dynamics.

In general terms, two of these ratifications stand out. First, the crisis affecting the written press is verified (only 39.8 per cent of the population read newspapers), the predominance of television is confirmed (88.6 per cent watch television) and the huge dimensions of the digital divide are corroborated (only 26.6 per cent of the population use Internet). The second ratification concerns the fact that no one media is capable of coordinating and covering the Catalan communication system as a whole. The three main areas (Catalonia, the 
Valencian Country and the Balearic Islands) operate somewhat in a vacuum, having little contact with each other in terms of media consumption. Furthermore, those responsible for drawing together this sphere of communication are the Spanish media, whose activities are grounded on a state-based logic. Thus, one of the great contradictions that has historically gripped the Catalan communication system is perpetuated (Tresserras 2000). This raises serious doubts about the existence and the future construction of this system as an autonomous communication space.

This lack of locally produced media to support the Catalan communication system is especially evident in the written press. Barometer data from 2007 reveal that no newspaper is capable of playing this role. Indeed, the large Barcelona papers (El Periódico de Catalunya and La Vanguardia) are scarcely read in the Valencian Country and the Balearic Islands. Similarly, the Valencian and Balearic press is incapable of reaching beyond the boundaries of their own regions. The study also evidences the success of the popular press model, since, on a general level, four of the six leading newspapers are of this type. Taken together, the quality press has a total of 1,008,000 readers per day as compared to the $2,251,000$ reported by the popular press.

Concerning radio, the barometer reveals the growing strength of the all-music stations, led by 'Los 40 Principales'. Of the all-talk stations, with the exception of Catalonia where Catalunya Ràdio leads with 534,000 listeners, 'Cadena SER' has the highest audiences. This data exposes the weakness of the regional public radio station in both the Balearic Islands, where IB3 Ràdio has only 6,000 listeners, essentially because it is a young station, but particularly in the Valencian Country where, as a result of lassitude and political disinterest, 'Ràdio Nou' takes thirteenth place in the classification with only 46,000 listeners per day.

In the area of television, some of the above-mentioned parameters are repeated. Across all the Catalan-speaking areas, the large Spanish television companies ('Antena 3' and 'Tele 5') have the largest audience share according to the barometer's 2007 data. In addition, only 27.6 per cent watch television in their own language, compared to 68 per cent of viewers who do so in Spanish. Despite the fact that in Catalonia the public regional television company, TV3, is the audience leader with a share of 20.8 per cent, its impact in the Balearic Islands and the Valencian Country is negligible: 3 per cent and 0.5 per cent respectively.

Among the most notable of the barometer's revelations, three are worth particular mention. First, the data shows that the 25-44-year-old target audience predominates in consumption of cultural and media products, taking the top position in all sections covered in the study. Second, the 14-24-year-old audience listen to the radio more (54.2 per cent of this audience sector) than those over 65 (42.2 per cent), belying the notion that radio audiences consist of older generations. Finally, initial results from the barometer reveal that progress towards multimedia convergence is slow. To date, the use of mobile telephones to watch television or audiovisual content (only 0.2 per cent of the audience), 
access Internet ( 3 per cent of those surveyed), listen to the radio (6.5 per cent) or music (11.5 per cent) has incorporated very few new users.

\section{The question of access}

With the exception of a brief set of summaries provided free of charge on each of the three stages of the main questionnaire and on specific reports, access to barometer data is through prepayment. The FUNDACC offers personalised services for the exploitation of its database to create reports tailored to the needs of its potential clients. In this way, the barometer upholds an established tradition among audience measurement systems: charging for its services. This situation puts the question of access at the top of the agenda.

The problem of access particularly affects researchers studying the structure, the operating dynamics, and media and culture consumer tendencies in the Catalan communication system. One of the main obstacles these academics systematically face is the difficulty of accessing audience behaviour data. The global summaries provided are insufficient when one considers the wealth of data that an instrument like the barometer could offer. A fundamental innovation would therefore be to provide access to academics who put forward serious and rigorous research projects with no financial gain to themselves; this access should not simply be at a reduced cost but free of charge, with the aim of contributing to a better understanding of the reasoning that governs the Catalan communication system. Naturally, it is coherent and desirable for the barometer to be capable of self-financing; however, resources should be derived from communication companies, which in turn must understand that the information this new instrument provides represents an added value with which to optimise their commercial strategies.

The full incorporation of academics into the barometer will only occur if they are able to integrate barometer data into their research and studies: therefore, barometer's commitment to improve calls for changes in the current parameters of action and the generalisation of the use of its data among the academic community. This can only be achieved through a policy that facilitates access to its representatives in regulated yet advantageous conditions. Only then will the barometer truly provide the infrastructure to serve the Catalan country and culture, as those responsible for its management claim (Cardús 2008).

This new instrument clearly serves an important purpose in offering information of exceptional interest. Its information not only contributes to guiding market strategies in the cultural industries operating in the Catalan-speaking areas, by improving benefits and effectiveness for advertisers, but will also provide the base on which to design and unfold public policies addressed to strengthen the Catalan communication system. The barometer offers a historical opportunity to expand knowledge on Catalan audience behaviour, as regards media and culture, from an empirical viewpoint. In today's globalised context, it is increasingly vital to shed light on the Catalan communication system. In sum, it plays a fundamental role in standardising the Catalan communication system once and for all. 


\section{References}

Busquet, Jordi (2008), 'L'espai català de cultura i comunicació. Realitat o virtualitat', Trípodos, Extra 2008, in memoriam Daniel E. Jones, pp. 185-190.

Cardús, Salvador et al. (2007), El Baròmetre i les necessitats estadístiques del sector de la comunicació, Barcelona: Generalitat de Catalunya.

Cardús, Salvador (2008), 'El Baròmetre de la Comunicació i la Cultura: una infraestructura de país', Cultura, 2 , pp. 224-231.

Gifreu, Josep (1983), Sistema i polítiques de comunicació a Catalunya. Premsa, ràdio, televisió i cinema, Barcelona: L’Avenç.

Gifreu, Josep and Corominas, Maria (eds) (1991), Construir l'espai català de comunicació, Barcelona: Centre d'Investigació de la Comunicació.

Gifreu, Josep (2006), La pell de la diferència. Comunicació, Ilengua i cultura des de l'espai català, Barcelona: Pòrtic.

Gifreu, Josep (2007), '20 anys de l'espai català de comunicació', Documents, 8, http://www.escacc.org/docroot/escacc/pdf/Conferencia_escacc.pdf. Accessed 13 December 2008.

Moragas, Miquel de (2008), 'Communication and Cultural Policies of Non-State Nations: The Experience of Catalonia', in Isabel Fernández Alonso and Miquel de Moragas (eds), Communication and Cultural Policies in Europe, Barcelona: Generalitat de Catalunya, pp. 271-290.

Tresserras, Joan Manuel (2000), 'La comunicació a la Catalunya del segle XX', L'Avenç, 243, pp. 68-74. 